University of Wollongong

Research Online

Faculty of Engineering and Information

Faculty of Engineering and Information

Sciences - Papers: Part A

Sciences

$1-1-2016$

New configuration of transverse reinforcement for improved seismic resistance of rectangular RC columns: concept and axial compressive behavior

D H. Jing

Southeast University

$\mathrm{T} \mathrm{Yu}$

University of Wollongong, taoy@uow.edu.au

$X$ D. Liu

Southeast University

Follow this and additional works at: https://ro.uow.edu.au/eispapers

Part of the Engineering Commons, and the Science and Technology Studies Commons

Research Online is the open access institutional repository for the University of Wollongong. For further information contact the UOW Library: research-pubs@uow.edu.au 


\title{
New configuration of transverse reinforcement for improved seismic resistance of rectangular RC columns: concept and axial compressive behavior
}

\author{
Abstract \\ Columns are considered to be critical members of moment-resisting structural systems. In seismically \\ active regions, it is important to improve the ductile deformation capacity and energy dissipation capacity \\ of columns so that the entire structure can endure severe ground motion and dissipate a considerable \\ amount of seismic energy. Against this background, this paper presents the idea of a new transverse \\ reinforcement configuration (TRC) for improved seismic performance of rectangular (including square) \\ reinforced concrete (RC) columns. The novel features of the new TRC compared to conventional TRCs \\ using rectangular hoops and cross ties mainly include the use of additional small circular spirals near the \\ column ends (i.e., potential plastic hinge regions). Such a simple change can significantly enhance the \\ performance of RC columns without complicating their construction. In this paper, the rationale for the \\ new TRC together with its expected advantages is first explained. A series of axial compression tests on \\ $\mathrm{RC}$ columns with the new TRC are then presented to demonstrate some of the expected advantages. The \\ test results confirmed that the concrete is very effectively confined by the new TRC, leading to significant \\ enhancements in both the load capacity and ductility of RC columns.

\section{Disciplines} \\ Engineering | Science and Technology Studies

\section{Publication Details} \\ Jing, D. H., Yu, T. \& Liu, X. D. (2016). New configuration of transverse reinforcement for improved seismic \\ resistance of rectangular RC columns: concept and axial compressive behavior. Engineering Structures, \\ $111383-393$.
}




\title{
NEW CONFIGURATION OF TRANSVERSE REINFORCEMENT FOR
}

IMPROVED SEISMIC RESISTANCE OF RECTANGUALR RC

COLUMNS: CONCEPT AND AXIAL COMPRESSIVE BEHAVIOR

\author{
D. H. Jing a,* T. Yu ${ }^{\text {b }}$ X. D. Liu ${ }^{a}$ \\ ${ }^{a}$ School of Civil Engineering, Southeast University, Nanjing 210096, China \\ ${ }^{b}$ School of Civil, Mining and Environmental Engineering, Faculty of Engineering and Information Sciences, \\ University of Wollongong, NSW 2522, Australia
}

\begin{abstract}
Columns are considered as critical members in moment-resisting structural systems. In seismic regions, it is important to improve the ductile deformation capacity and energy dissipation capacity of columns so that the entire structure can endure severe ground motions and dissipate a considerable amount of seismic energy. Against this background, this paper presents the idea of a new transverse reinforcement configuration (TRC) for improved seismic performance of rectangular (including square) reinforced concrete (RC) columns. The novel features of the new TRC, compared to conventional TRCs using rectangular hoops and cross ties, include mainly the use of additional small circular spirals near the column ends (i.e. potential plastic hinge regions). Such simple change can significantly enhance the performance of RC columns, but does not introduce much difficulty in construction. In this paper, the rationale for the new TRC together with its expected advantages is first explained. A series of axial compression tests on RC columns with the new TRC are then presented to demonstrate some of the expected advantages. The test results confirmed that the concrete is very effectively confined by the new TRC, leading to significant enhancement in both the load capacity and the ductility of RC columns.
\end{abstract}

\footnotetext{
* Corresponding author. Address: School of Civil Engineering, Southeast University, 210096 Nanjing, China. Tel.: +86 02583694929 ; fax: +8602583191253 . E-mail address: jingdh@ seu.edu.cn (D.H. Jing).
} 
Keywords: columns; concrete; transverse reinforcement configuration; confinement; seismic performance; ductility

\section{Introduction}

Columns are considered as critical members in moment-resisting structural systems. A recent survey following the 2008 magnitude $\left(M_{s}\right)$ 8.0 Wenchuan earthquake revealed that the most severe damage in reinforced concrete (RC) structures occurred at the column ends of bottom story (stories) (Fig. 1). This observation was similar to the findings in other major earthquakes including the 1994 Northridge earthquake [1] and the 1999 Taiwan earthquake [2]. Such column-end damage was generally in the form of concrete crushing associated with buckling of longitudinal reinforcement [3], and appeared to be more pronounced in rectangular (including square) columns than in circular columns [4]. The severe column-end damage may lead to a partial or a total collapse of the whole structure. Even in the less severe cases where the structures still stand, it is often difficult to repair/rehabilitate them to a functional state because of the excessive and unequal settlement of the upper stories caused by the column damage in the bottom story (stories). While the column-end damage is generally caused by multiple simultaneous factors, the lack of ductility of columns is deemed to be one of the most important factors [5]. Therefore, it is important to improve the ductile deformation capacity and energy dissipation capacity of columns so that the entire structure can endure severe ground motions and dissipate a considerable amount of seismic energy. 


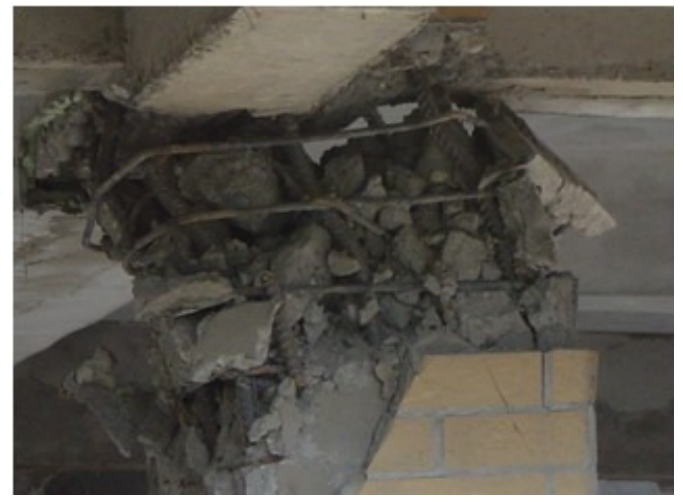

(a) Inner column

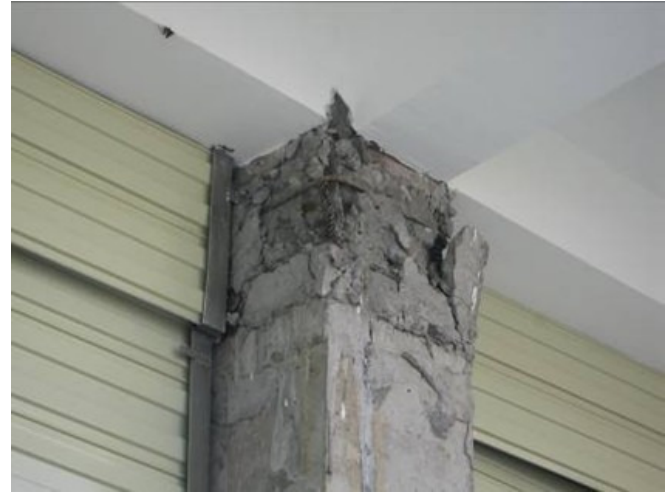

(b) Side column

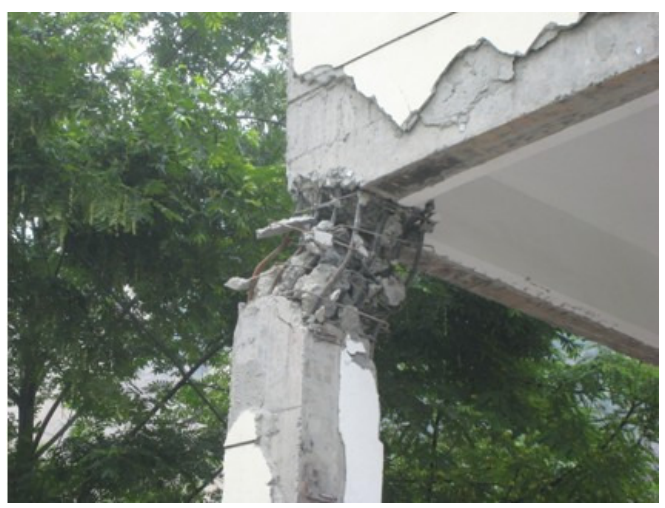

(c) Corner column

Fig.1 Failure at column ends of RC frames in Wenchuan earthquake

It has been well known that both the strength and the ductility of concrete can be significantly enhanced when subjected to confinement [6]. Extensive research has been conducted to improve the seismic performance of RC columns making use of various types of confinement (e.g. [5, 7-8]). Examples included the use of short steel tubes (e.g. [9-11]), welded grids (e.g. [12]), welded wire fabric sheets (e.g. [13]), and continuous hoops (e.g. [14]) as additional confinement to the concrete either at the column ends or all over the column. Fiber-reinforced polymer (FRP) jackets have also emerged in the past two decades as an effective confining material for seismic strengthening as well as for new construction [15-17]. Despite the use of different confining materials, these studies generally found that the confinement is much more efficient in circular columns than in rectangular (including square) columns [6, 18-19]. 
With the aim of improving confinement effectiveness, a number of studies have also been conducted to explore the optimization of column shape as well as configuration of transverse reinforcement. In the early 1980s, the California Department of Transportation (CALTRANS) proposed the so-called interlocking spirals in compression members for bridge structures designed for seismic loading (Fig. 2) [20-21]. The cross-section shown in Fig. 2, as a variation of rectangular section, is particularly suitable for use as bridge piers which are subjected to different load levels in the two horizontal directions. Among other benefits of using interlocking spirals, one important advantage of the cross-section (Fig. 2) is the more effective confinement received by the two parts of concrete surrounded by the two circular spirals respectively; such effective confinement consequently leads to enhanced ductility and energy dissipation capacity of the column. Bridge piers with the cross-section shown in Fig. 2 have thus received extensive research attention afterwards (e.g. [22-28]). More recently, Ou et al. [29] proposed an innovative sevenspiral transverse reinforcement (Fig. 3) for oblong bridge columns, which might be seen as an extension of the interlocking spiral reinforcement shown in Fig. 2. The use of a larger number of spirals with a reduced size facilitates the fabrication and transportation of the reinforcement without affecting the excellent ductile performance of the column [29].

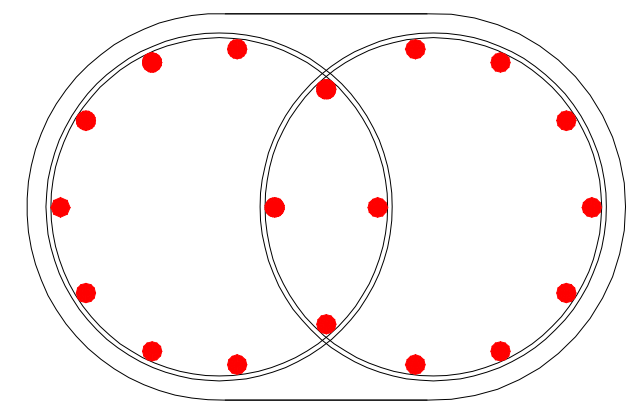

Fig. 2 Typical cross-section of bridge columns with interlocking spirals [20] 


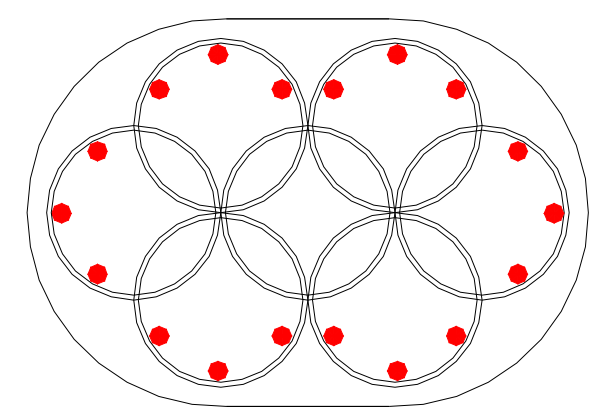

Fig. 3 Bridge columns with seven-spiral reinforcement [29]

While it is structurally sound, the cross-sections shown in Figs. 2 and 3 are generally not preferred in buildings due to constructability reasons especially the difficulties/costs in manufacturing/assembling the formwork for casting concrete. In buildings, rectangular (including square) columns are often preferred, for which standard formwork can be easily assembled to suit different sizes as per design requirements. Yin and his co-workers [30-41] have recently attempted to extend the concept of interlocking spirals to rectangular/square columns for building structures. Yin [30-31, 36] proposed several configurations of transverse reinforcement for square columns, and demonstrated through experimental tests that their proposed variations of transverse reinforcement configurations (referred to as "TRCs" hereafter), especially that shown in Fig. 4a (i.e. five-spiral transverse reinforcement), can lead to significant strength and ductility enhancement of the columns [31]. Weng et al. [33-34] then used the five-spiral transverse reinforcement in concrete-encased steel columns and demonstrated its effectiveness in such applications. Based on a similar concept, Weng et al. [35] and Shih et al. [40] proposed a new TRC (Fig. 4b) for square columns where a circular spiral is interlocked with a star-shaped spiral for improved confinement effectiveness. Similar designs have also been explored by other researchers, including $\mathrm{Wu}$ et al. [41] who proposed the so-called six-spiral transverse reinforcement (Fig. 4c). Columns with these interlocking spiral TRCs generally possess better strength and ductility than those with conventional rectilinear reinforcement when the amount of transverse reinforcement is the same $[31,41]$. 
The TRCs proposed by these existing studies (i.e. Fig. 4), however, generally involve the use of one or more large spirals which are difficult and/or uneconomical to fabricate. Furthermore, these proposed TRCs (e.g. Fig. 4) may lead to significant changes in the configuration and/or amount of longitudinal reinforcement, which may not be structurally efficient in resisting flexure (e.g. Fig. 4a), and/or may cause congestion at the beam-column connections (e.g. Figs. 4b and 4c).

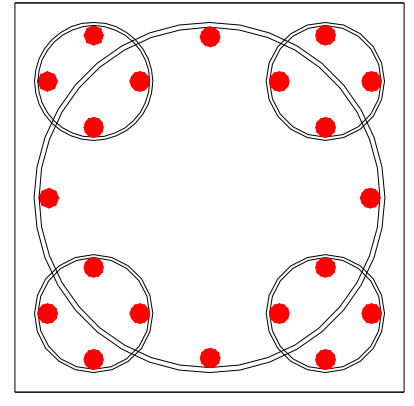

(a) $[31]$

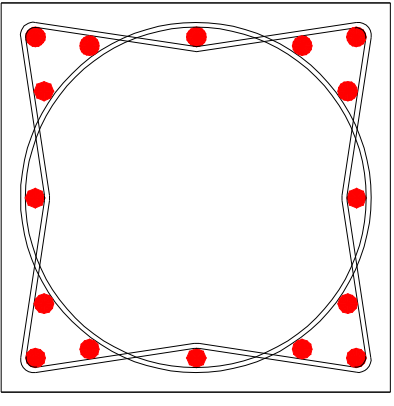

(b) $[35,40]$

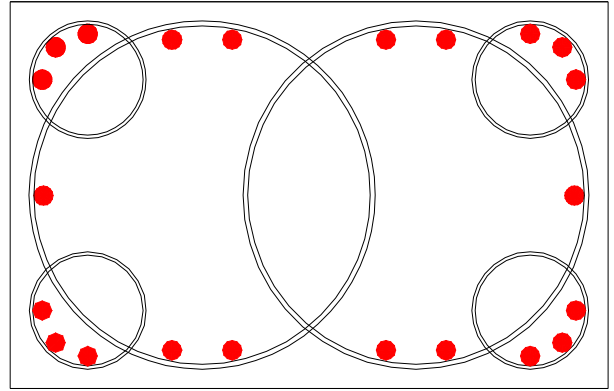

(c) $[41]$

Fig. 4 Typical cross-sections of rectangular columns with interlocking spirals Against this background, this paper presents the idea of a new configuration of transverse reinforcement, which possesses several advantages not available to the existing solutions, for the purpose of improved seismic performance of rectangular (including square) RC columns. This paper also presents results from the first series of compression tests to evaluate the axial behavior of columns with the new TRC.

\section{New transverse reinforcement configuration}

In a rectangular $\mathrm{RC}$ column, the conventional transverse reinforcement consists of rectangular hoops, as well as cross ties especially when the width/depth of the cross-section is large (Fig. 5b). For improved seismic resistance, a smaller spacing is normally adopted for rectangular hoops near the ends of columns [42]. However, the denser rectangular hoops in the end portions of columns 
only lead to limited improvement in the ductility of the column (Fig. 1), due to the fact that the confinement provided by such hoops relies mainly on their flexural stiffness which is often rather limited when compared to their tensile stiffness.

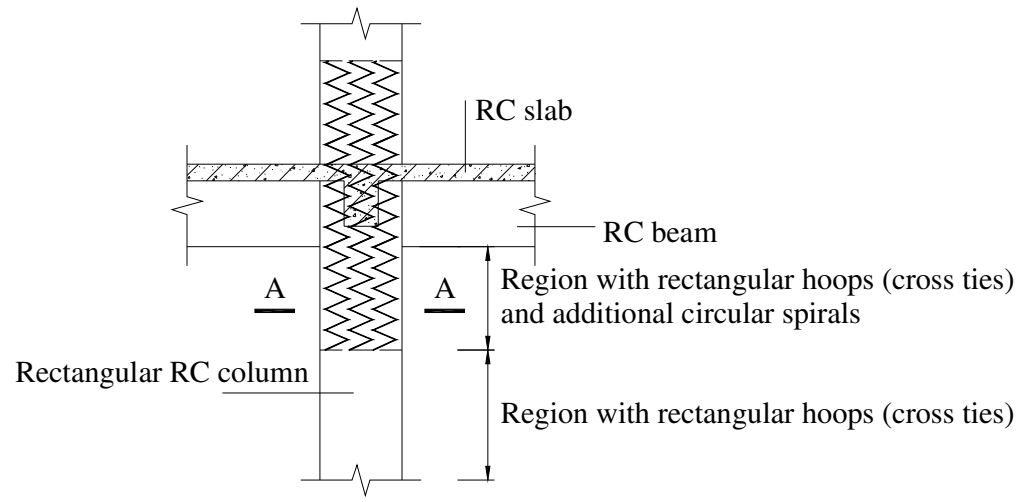

(a) Elevation



(b) Section A-A

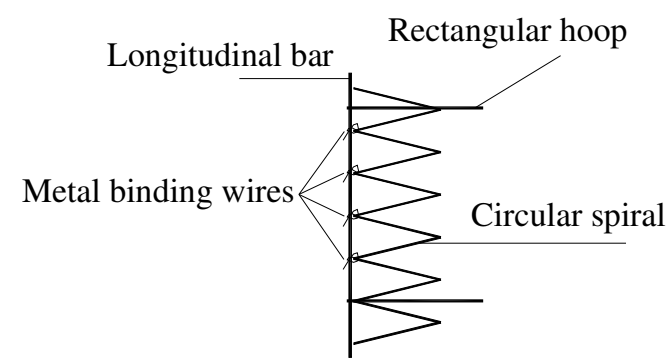

(c) Details of additional connection

Fig. 5 Typical rectangular RC column with the proposed new TRC at column ends

To overcome the disadvantages arising from the ineffective confinement of rectangular hoops, a new transverse reinforcement configuration (TRC) has recently been proposed by the authors. The new TRC consists of rectangular hoops, cross-ties, and additional circular spirals provided only in the end portions (i.e. potential plastic hinge regions) of the column (Fig. 5a). All the circular spirals are interconnected by cross-ties (Fig. 5b) which have been shown to be effective in preventing premature vertical shear cracks when the column is subjected to high shear loads [27]. Except for the ones at the corners, each longitudinal bar is placed inside one of the circular spirals so that it receives sufficient confinement to minimize possible buckling deformation (Fig. 5b). The 
longitudinal bars at the corners typically receive more efficient confinement from the rectangular hoops, and can be further tied to the circular spirals using metal binding wires when necessary (Fig. 5c). With the new TRC, the concrete inside each circular spiral is very well confined; such wellconfined concrete together with the longitudinal reinforcement within the same circular spiral form a number of small confined cylinders which possess excellent ductility as well as a much higher bending stiffness to resist buckling than individual longitudinal bars. These confined cylinders also provide additional confinement to the concrete surrounded by them, leading to further improved ductility of the column. The rectangular hoops and cross ties not only contribute directly to the shear resistance, but also play an important role of providing lateral constraints to and allowing effective shear transfer between the small confined cylinders. Hereafter, the new TRC is referred to as multiple-tied-spiral transverse reinforcement or MTSTR for simplification.

The novel features of the MTSTR compared to typical TRCs in practice include mainly the use of additional small circular spirals near the column ends instead of merely denser rectangular hoops. Such simple change can significantly enhance the performance of RC columns as discussed above, but does not introduce much difficulty in construction. The only additional procedure in construction is to fix the circular spirals to longitudinal bars in the end column portions, which can be easily done when producing the steel cage. The configuration of longitudinal bars with the MTSTR is almost identical to that in current practice except that some of the longitudinal bars may need to be slightly adjusted along one side of the section so that each of them sits in one circular spiral (see Fig. 5b). Such slight adjustment does not affect the effectiveness of longitudinal bars in resist bending and is not a problem for construction.

Compared with the TRCs proposed by Yin et al.[30-31, 36], Weng et al. [35], Shih et al. [40] and Wu et al. [41], the advantages of the MTSTR are apparent: (1) efficient use of longitudinal bars to resist bending as they are placed away from the centroid of the section; (2) ease for construction as changes to the current construction practice are minimized; the use of spirals with a reduced size 
also facilitates the fabrication and transportation of the reinforcement. The MTSTR therefore has great potential especially in regions where the automatic fabrication of large spirals is difficult or impossible.

\section{Experimental program}

\subsection{General}

Obviously, for the MTSTR to be used in practical applications, a great deal of research is required to develop reliable design methods, for which one important issue is to understand the behavior of the confined concrete in such columns. As a first step, a series of axial compression tests on square columns with the MTSTR were conducted. Axial compression tests provide useful insights into the confinement mechanism and a valuable measure of the ductility of the column [43]. Such tests also provide test data for the development of a monotonic stress-strain model of the confined concrete, which may be used for predicting the envelope curve of cyclic stress-strain curves [4445]. The experimental program was limited to square columns which are widely used in buildings when the load levels in the two horizontal directions are comparable. Results obtained from the tests of square columns also lay a good foundation for future research into rectangular columns with the MTSTR. The axial compression tests presented here were mainly focused on the behavior of the confined concrete, so only nominal longitudinal bars (i.e. 4 bars with a diameter of $6 \mathrm{~mm}$ ) were provided for ease of producing the reinforcement cage.

\subsection{Test specimens}


In total, 12 square column specimens were prepared and tested, including 10 specimens with the MTSTR and 2 plain concrete columns as reference specimens. The specimens all had a cross section of $250 \mathrm{~mm} \times 250 \mathrm{~mm}$, and an overall height of $900 \mathrm{~mm}$ with the middle region of $400 \mathrm{~mm}$ as the test region. The two regions (each being $250 \mathrm{~mm}$ in height) near the column ends were heavily reinforced to avoid unexpected failure there. After the testing of the first specimen (i.e. specimen CHA-4-1) where premature failure still occurred near the column ends, the two end regions of all the other specimens were further strengthened using one layer of carbon fiber reinforced polymer (CFRP) wrap which successfully ensured that failure happened within the test region. These columns were cast in 2 batches (i.e. batches $\mathrm{L}$ and $\mathrm{H}$ ) with 2 different concrete mix ratios respectively to produce 2 different concrete grades. Three different types of TRCs were used, with the main differences being the diameter and number of the circular spirals, as shown in Fig. 6. Other test variables included the vertical spacing of the circular spirals and that of the rectangular hoops. The details of all specimens are summarized in Table 1 , where all the numbers refer to the values for the test region. The specimens before tests are shown in Fig. 7a.

Table 1 Details of specimens

\begin{tabular}{|c|c|c|c|c|c|c|}
\hline Specimen & $\begin{array}{c}\text { Type } \\
\text { of } \\
\text { TRC }\end{array}$ & $\begin{array}{c}\text { Number } \\
\text { of spirals }\end{array}$ & $\begin{array}{c}\text { Vertical } \\
\text { spacing of } \\
\text { spirals, s(mm) }\end{array}$ & $\begin{array}{c}\text { Diameter of } \\
\text { spirals, D } \\
(\mathrm{mm})\end{array}$ & $\begin{array}{c}\text { Spacing of } \\
\text { rectangular } \\
\text { hoops, d (mm) }\end{array}$ & Batch \\
\hline CLC-4-1 & C & 4 & 40 & 70 & 100 & $\mathrm{~L}$ \\
\hline CLB-4-1 & B & 4 & 40 & 100 & 100 & $\mathrm{~L}$ \\
\hline CLA-4-2 & A & 8 & 40 & 70 & 200 & $\mathrm{~L}$ \\
\hline CLA-4-1 & A & 8 & 40 & 70 & 100 & $\mathrm{~L}$ \\
\hline CLA-6-1 & A & 8 & 60 & 70 & 100 & $\mathrm{~L}$ \\
\hline CLA-8-1 & A & 8 & 80 & 70 & 100 & $\mathrm{~L}$ \\
\hline CL & - & 0 & - & - & - & $\mathrm{L}$ \\
\hline CHA-4-1 & A & 8 & 40 & 70 & 100 & $\mathrm{H}$ \\
\hline CHB-4-1 & B & 4 & 40 & 100 & 100 & $\mathrm{H}$ \\
\hline CHA-6-1 & A & 8 & 60 & 70 & 100 & $\mathrm{H}$ \\
\hline CHA-4-2 & A & 8 & 40 & 70 & 200 & $\mathrm{H}$ \\
\hline CH & - & 0 & - & - & - & $\mathrm{H}$ \\
\hline
\end{tabular}


Each specimen was given a name, which starts with the letter "C" to represent "column", followed by a letter " $\mathrm{L}$ " or " $\mathrm{H}$ " to represent the concrete batch. For the specimens with the MTSTR, this is then followed by another letter (i.e. "A", "B" or "C") to represent the type of TRCs (see Fig. 6), and then two numbers which define the vertical spacing of the circular spirals (in $\mathrm{cm}$ ) and that of the rectangular hoops (in $\mathrm{dm}$ ) respectively. For example, specimen CL is the reference specimen in batch L, while CHA-4-1 is a specimen which was cast in batch $\mathrm{H}$ and had type A TRC, circular spirals with a vertical spacing of $40 \mathrm{~mm}$ and rectangular hoops with a vertical spacing of $100 \mathrm{~mm}$.

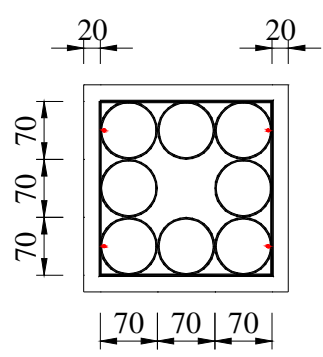

Type A

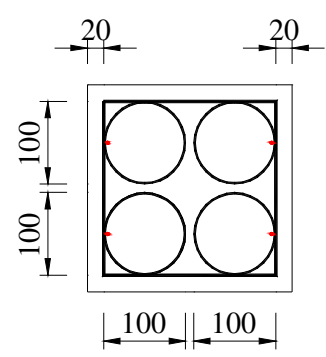

Type B

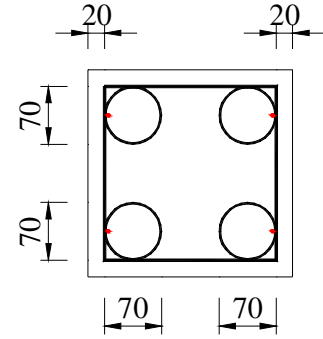

Type C

(a) Three types of TRCs

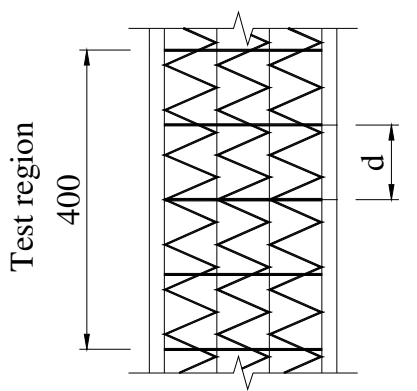

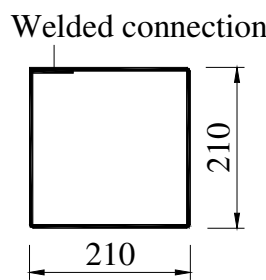

Rectangular hoop

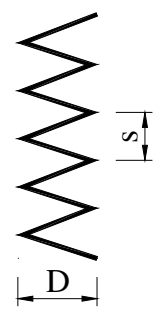

Spiral

(b) Test region with type A TRC

Fig.6 Details of test specimens 


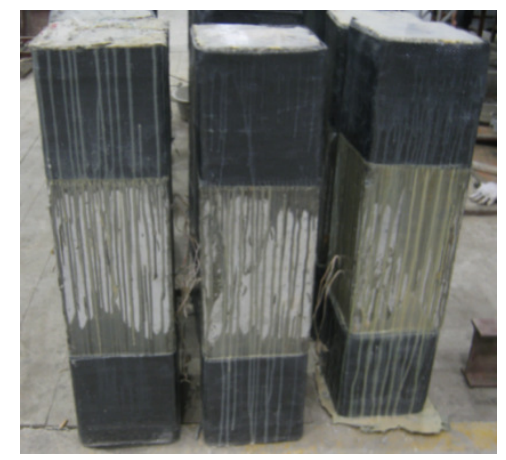

(a) Specimens before tests

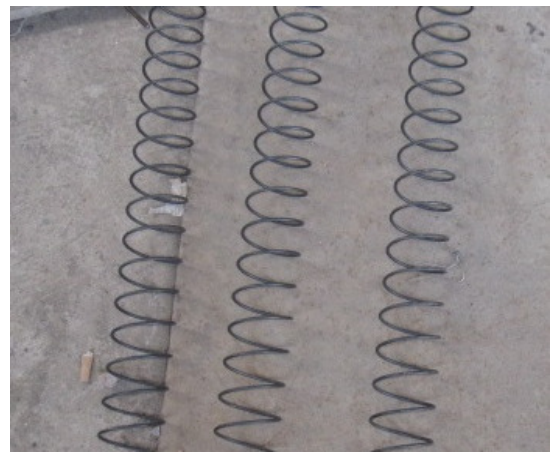

(b) Spirals

Fig. 7 Preparation of test specimens

\subsection{Material properties}

The concrete was prepared in two batches with ordinary Portland cement, fly ash, river sand, and granite aggregate with a maximum nominal size of $15 \mathrm{~mm}$. Three plain concrete cubes (150 mm in width) were tested following GB/T 50081-2002 [46] for each batch to determine the 28-day compressive strength of concrete. The results from these tests are given in Table 2.

The circular spirals (see Fig. 7b) used in all reinforced specimens were made of heat-treated $65 \mathrm{Mn}$ steel round bars with a diameter of $4 \mathrm{~mm}$, and were prefabricated by a local factory. High-strength steel spirals were selected so that their confinement effect was more pronounced. The rectangular hoops were made of mild steel round bars with a diameter of $6 \mathrm{~mm}$; the same bars were also used as longitudinal reinforcement. Tensile tests of both types of steel reinforcement were conducted following GB/T 228.1-2010 [47], and the test results are also summarized in Table 2.

Table 2 Measured material properties 


\begin{tabular}{|c|c|c|c|c|}
\hline \multicolumn{2}{|c|}{ Material } & $\begin{array}{c}\text { Yield stress } \\
(\mathrm{MPa})\end{array}$ & $\begin{array}{c}\text { Ultimate stress } \\
(\mathrm{MPa})\end{array}$ & $\begin{array}{c}\text { Elastic modulus } \\
(\mathrm{MPa})\end{array}$ \\
\hline \multirow{2}{*}{ Concrete } & Batch L & $/$ & 51.4 & $/$ \\
\cline { 2 - 5 } & Batch H & $/$ & 60.0 & $/$ \\
\hline \multirow{2}{*}{$\begin{array}{c}\text { Steel } \\
\text { reinforcement }\end{array}$} & $65 \mathrm{Mn}$ steel & 1196.7 & 1349.7 & $2.1 \times 10^{5}$ \\
\cline { 2 - 5 } & Mild steel & 344.7 & 503.6 & $2.0 \times 10^{5}$ \\
\hline
\end{tabular}

\subsection{Test set-up and instrumentation}

For each specimen, four linear variable displacement transducers (LVDTs) were used to obtain the axial deformation of the $400 \mathrm{~mm}$ mid-height region of each specimen. In addition, two LVDTs were used to measure the overall axial shortening of the specimens. All compression tests were carried out using a column testing facility with a capacity of $10000 \mathrm{kN}$ (Fig. 8). All test data, including the strains, loads, and displacements, were recorded simultaneously by a data logger.

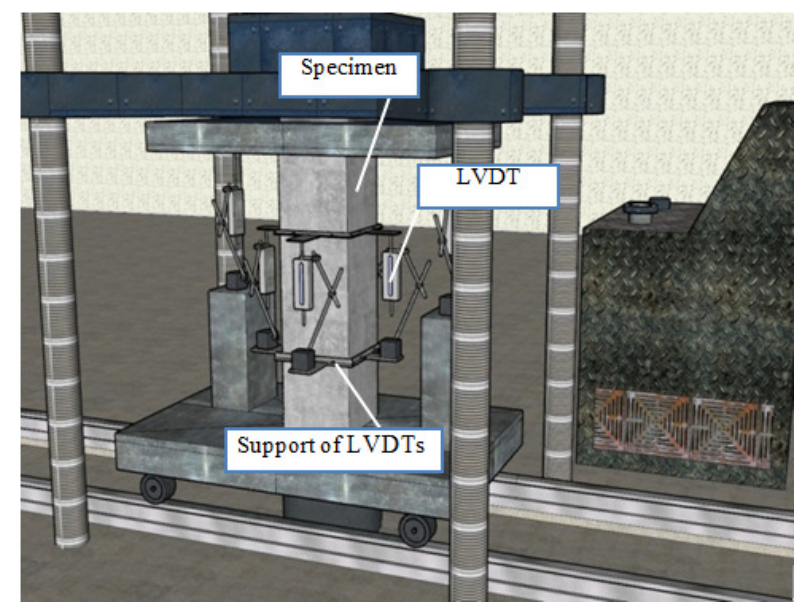

(a) Schematic diagram

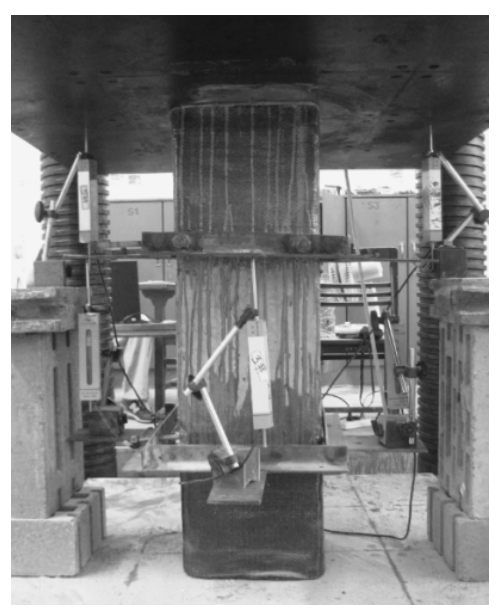

(b) Specimen during test

Fig. 8 Test setup

In the initial stage of loading, the load was applied at an increment of $100 \mathrm{kN}$ per step; the load increment per step was then reduced to $50 \mathrm{kN}$ after the axial load-shortening behavior of the specimens started to become nonlinear. After the peak load, the displacement increment per step was carefully selected to obtain a smooth descending branch of axial load-shortening curves. After 
each step of loading, the specimens were allowed sufficient time to get stabilized before the readings were taken.

\section{Test results and discussions}

\subsection{Damage process}

The progress of damage of the columns with the MTSTR was generally different from that of conventional square RC columns with square hoops and cross ties. Four distinct stages of damage process were observed (referred to as stages 1 to 4 hereafter): (1) the column deformed approximately linearly until the first sign of damage which was indicated by a vertical crack close to one of the column corners (Fig. 9a); this crack normally occurred when the load reached around the peak load of the corresponding reference plain column, and had an initial length of around 45 $\mathrm{mm}$ when it became noticeable; (2) with the loading process, more cracks occurred and these cracks kept growing which led to the spalling of cover concrete and the exposure of the reinforcement (Fig. 9b); (3) the small concrete cylinders confined by the circular spirals were then seen to develop lateral deformation because of the expansion of the concrete surrounded by them (Fig. 9c); such lateral deformation of the confined cylinders was generally associated with visible cracks between them, and was restrained by the rectangular hoops; the peak load was reached in this stage for all columns with the MTSTR; and (4) the lateral deformation of the confined cylinders, associated with crushing of the concrete outside them, became increasingly large and finally led to rupture of the rectangular hoops and/or circular spirals (Fig. 9d). 


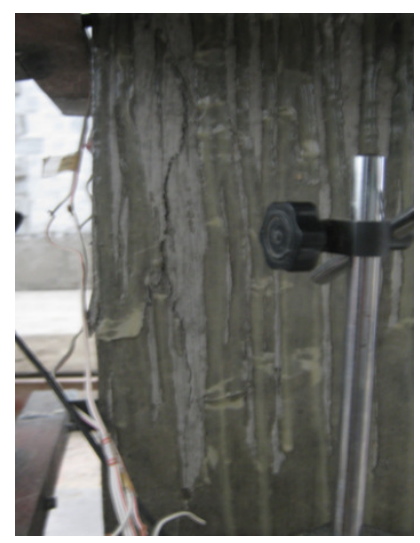

(a) Vertical crack near column corner

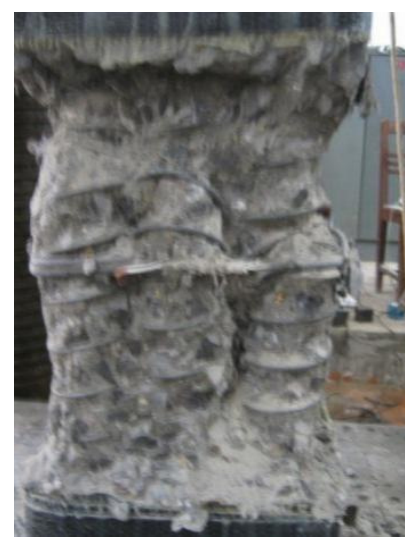

(c) Lateral deformation of confined cylinders

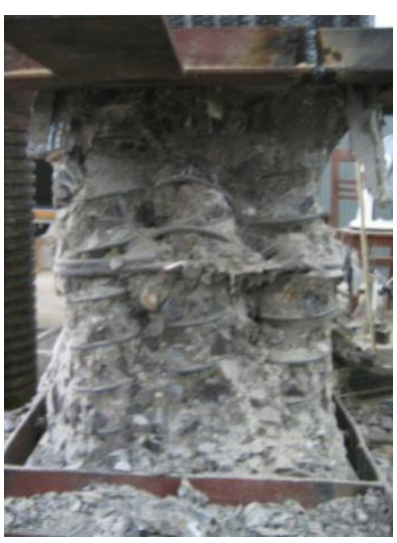

(b) Spalling of cover concrete

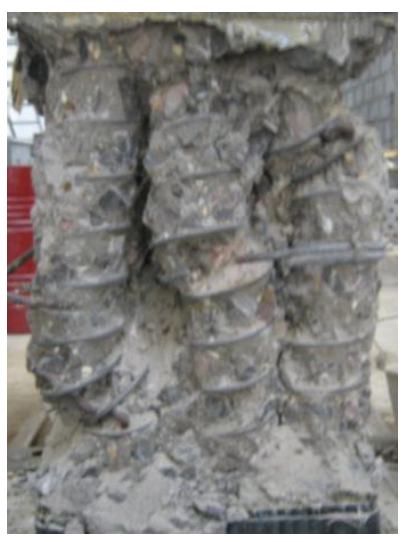

(d) Rupture of transverse reinforcement

Fig. 9 Damage process of columns with the MTSTR

\subsection{Axial load-axial strain behavior}

The peak loads of the two reference plain concrete specimens (i.e. $\mathrm{CL}$ and $\mathrm{CH}$ ) were $2600 \mathrm{kN}$ and $2850 \mathrm{kN}$ respectively, while the corresponding axial strains were 0.00296 and 0.00253 respectively. Table 3 provides a summary of the key test results of all specimens with the MTSTR except for specimen CHA-4-1 which experienced premature failure close to the column ends and is thus excluded from further discussions here. In this table, $P_{c}$ is the peak load of the specimens from the tests, $\varepsilon_{c c}$ is the axial strain corresponding to the peak load, $\varepsilon_{u}$ is the axial strain 
corresponding to $85 \%$ of the peak load on the descending branch of axial load-axial strain curves, and $P_{c o}$ and $\varepsilon_{c o}$ are the peak load of the reference plain specimens and the corresponding axial strain, respectively.

Table 3 Key test results

\begin{tabular}{|c|c|c|c|c|c|c|c|c|}
\hline Specimen & $P_{c}(\mathrm{kN})$ & $\varepsilon_{c c}$ & $\varepsilon_{u}$ & $P_{c} P_{c o}$ & $\varepsilon_{c c} \mathcal{E}_{c o}$ & $\varepsilon_{u} \varepsilon_{c o}$ & $\begin{array}{c}P_{0.02} \\
(\mathrm{kN})\end{array}$ & $\begin{array}{c}P_{0.03} \\
(\mathrm{kN})\end{array}$ \\
\hline CLC-4-1 & 2900 & 0.00634 & 0.01496 & 1.115 & 2.142 & 5.054 & 2093 & 1579 \\
\hline CLB-4-1 & 3100 & 0.01129 & 0.01761 & 1.192 & 3.814 & 5.949 & 2465 & 1310 \\
\hline CLA-4-2 & 3300 & 0.01457 & 0.01941 & 1.269 & 4.922 & 6.557 & 2738 & 1819 \\
\hline CLA-4-1 & 3350 & 0.01554 & 0.02091 & 1.288 & 5.250 & 7.064 & 2887 & 1862 \\
\hline CLA-6-1 & 2900 & 0.01030 & 0.01861 & 1.115 & 3.480 & 6.287 & 2319 & 1607 \\
\hline CLA-8-1 & 3000 & 0.00726 & 0.01120 & 1.154 & 2.453 & 3.784 & 1616 & 1054 \\
\hline CHB-4-1 & 3200 & 0.01113 & 0.02091 & 1.123 & 4.399 & 8.265 & 2832 & 1466 \\
\hline CHA-6-1 & 3200 & 0.01105 & 0.01545 & 1.123 & 4.368 & 6.107 & 1144 & 1102 \\
\hline CHA-4-2 & 3500 & 0.01153 & 0.01820 & 1.228 & 4.557 & 7.194 & 2834 & 2047 \\
\hline
\end{tabular}

The axial load-axial strain curves of the 9 specimens are shown in Fig. 10, where the axial strains were obtained from the readings of the four LVDTs covering the $400 \mathrm{~mm}$ mid-height region. For clarity of presentation, the curves in Fig. 10 are generally terminated at an axial strain close to 4\%, although most of them were tested to a larger axial strain. It is obvious that the specimens with the MTSTR reached peak loads and corresponding strains which were significantly higher than those of the reference specimens, with the increase in the peak load being up to $28.8 \%$ and that in the axial strain corresponding to peak load being up to $425 \%$. The ultimate strain (i.e. $\varepsilon_{u}$ ) of these columns reached up to over $2 \%$ with the $\varepsilon_{u} \varepsilon_{c o}$ value being up to 8.265 , indicating the excellent ductility of columns with the MTSTR. 


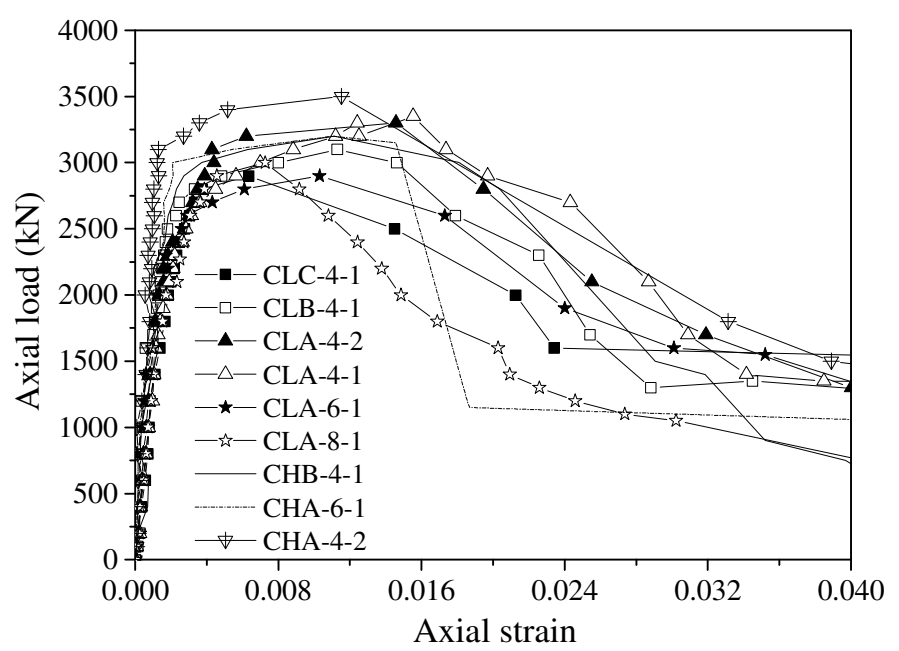

Fig. 10 Axial load-axial strain curves

The residual strength of RC columns after earthquake is an important factor affecting the settlement of the upper stories and the repairability of the building. The residual strengths of the 9 specimens corresponding to different axial strains can be extracted from Fig. 10. The residual strengths corresponding to an axial strain of $2 \%\left(P_{0.02}\right)$ were found to be around or over $80 \%$ for all the specimens except specimens CLA-8-1 and CHA-6-1 which had a small amount of circular spirals; the values corresponding to an axial strain of $3 \%\left(P_{0.03}\right)$ were found to be around or over $50 \%$ for most of the specimens (see Table 3).

\subsection{Confining mechanism}

In the tested columns with the MTSTR, only nominal longitudinal bars were provided, whose contribution to the overall load capacity of the column was generally smaller than $2 \%$. Therefore, the load taken by the column was mainly shared by three parts of concrete: cover concrete, concrete within the circular spirals and concrete within the rectangular hoops but outside the circular spirals (referred to as "core concrete outside spirals" hereafter). 
The axial load-axial strain curve of specimen CLA-4-1 is used here to illustrate the mechanism in a column with the MTSTR, as shown in Fig. 11. The curve can be divided into four portions (see Fig. 11) corresponding to the four stages of damage process described in the section 4.1. For comparison, three other curves are also plotted in Fig. 11: (1) the load-strain curve of the cover concrete which was derived from the curve of the corresponding reference column by assuming that the stress-strain behavior of the two was the same; (2) the load-strain curve of the concrete confined by the circular spirals, which was obtained using Mander et al.'s [45] model by assuming that the concrete received confinement only from the circular spirals; and (3) the load-strain curve of the core concrete outside spirals, which was obtained again using Mander et al.'s [45] model by assuming that the concrete received confinement only from the rectangular hoops. Fig. 11 shows that in stage 1 of loading (portion "OA" in Fig. 11), the three parts of concrete were generally in the elastic range, and all contributed positively to the overall load. The load taken by the cover concrete then continued to reduce until zero in the second stage of loading (portion "AB" in Fig. 11), but the total load taken by the other two parts of concrete increased at a higher rate because of the confinements they respectively received, so the overall load taken by the column still kept increasing in this stage. In stage 3 of loading (portion "BC" in Fig. 11), only the two parts of concrete within the rectangular hoops contributed to the overall load, among which the load taken by the core concrete outside spirals, as predicted by Mander et al.'s [45] model, was seen to have decreased significantly in this case. However, the overall load taken by the column was still increasing in this stage, owing largely to the contribution from the concrete inside the circular spirals which provided the most efficient confinement. It is interesting to note that the peak axial load of the column was reached at a strain which was close to that corresponding to the peak stress 
of the concrete inside circular spirals, demonstrating again the dominating effect of this part of concrete. After this part of concrete reached its peak stress, the column entered stage 4 (portion "CD" in Fig. 11) when the overall load started to decrease.

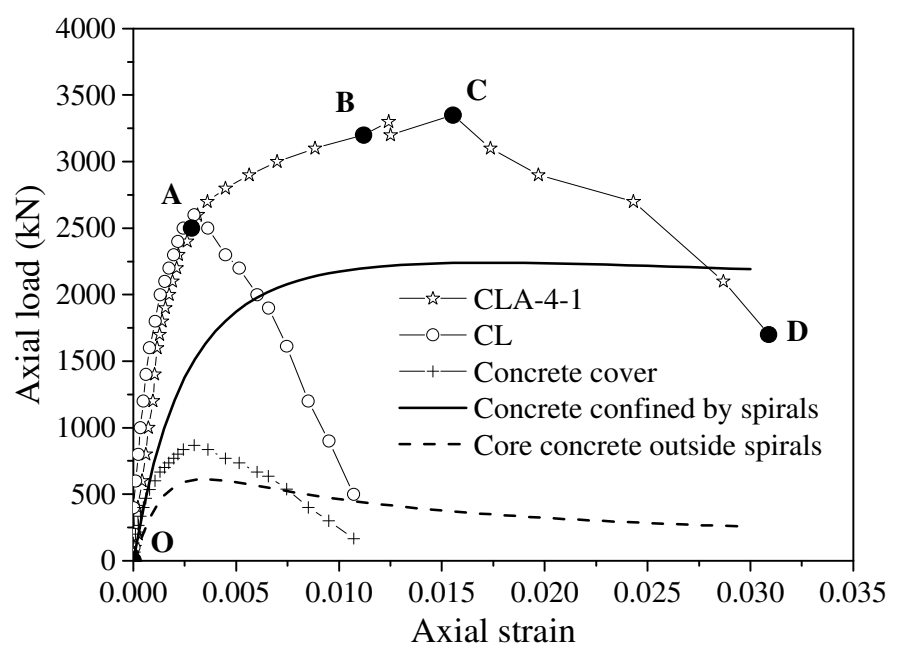

Fig.11 Further examination of typical axial load-axial strain curve

Based on the curves in Fig. 11, it is also interesting to note from a simple calculation that the peak load from the test of specimen CLA-4-1 (i.e. $3350 \mathrm{kN}$ ) was significantly higher than the sum (i.e. $2609 \mathrm{kN}$ ) of the loads taken respectively by the three parts of concrete at the same strain. Such difference is believed to come from the oversimplified assumptions adopted above that the concrete inside spirals only received confinement from spirals while the core concrete outside spirals only received confinement from rectangular hoops. As illustrated in Fig. 12, the core concrete outside spirals was also confined by the small confined concrete cylinders which possessed a large bending stiffness and could have behaved as a thick continuous confining wall; the concrete inside spirals was also constrained by the surrounding concrete and the rectangular hoops. The beneficial effect of such mechanism of interaction between different parts of concrete was significant: an increase of around $28 \%$ in the load capacity was seen for this case. 


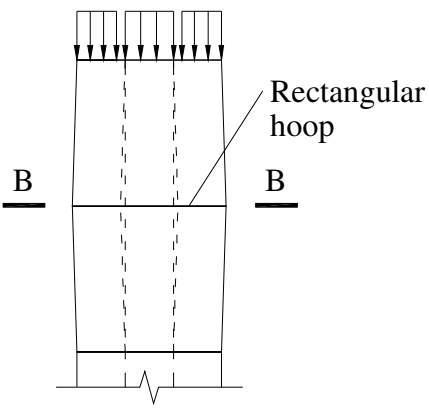

(a)

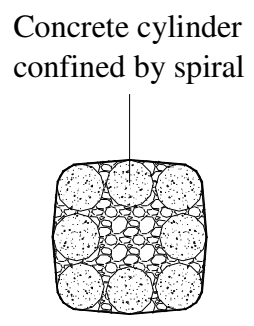

$\underline{\mathrm{B}-\mathrm{B}}$

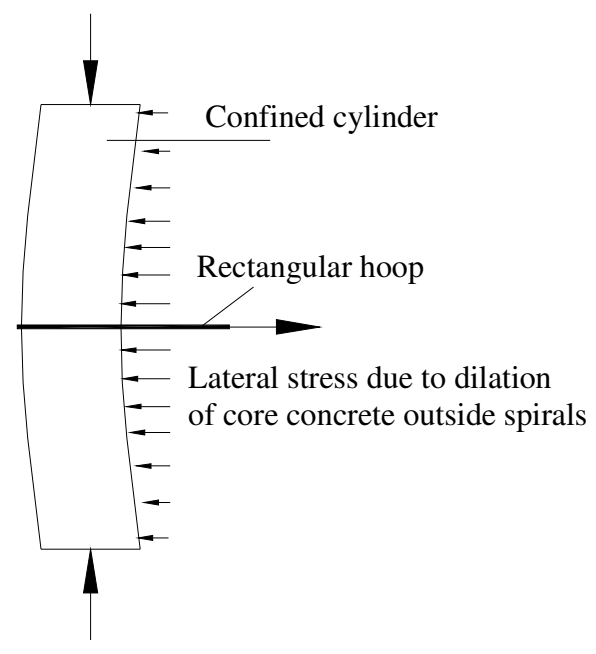

(c)

Fig.12 Mechanism of interaction between different parts of concrete/reinforcement

\subsection{Effect of different TRCs}

To examine the effect of using different types of TRCs, the axial load-axial strain curves of specimens CLA-4-1, CLB-4-1 and CLC-4-1 are compared in Fig. 13. The only difference between the three specimens was the use of different types of TRCs (see Fig. 6a).

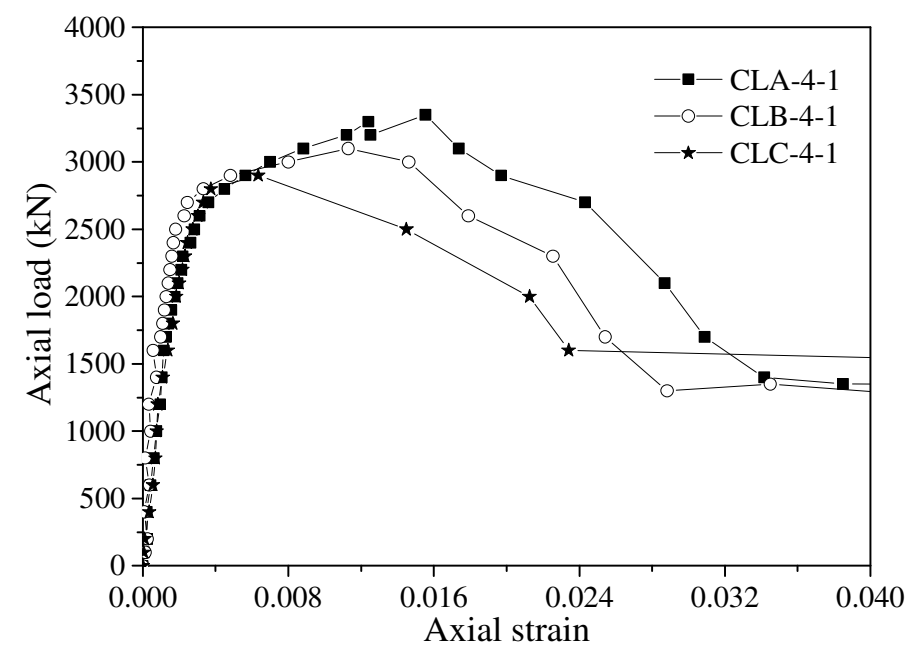

Fig. 13 Effect of different TRCs 
It is easy to understand that the performance of specimen CLA-4-1 was much better than that of specimen CLC-4-1 (see Fig. 13), as the former had eight $70 \mathrm{~mm}$ circular spirals while the latter only had four spirals of the same diameter. The area of concrete that was heavily confined (i.e. that within circular spirals) was thus much larger in specimen CLA-4-1, leading to a larger axial load capacity and better ductility. Different from specimen CLA-4-1 (see Fig. 13), the peak load of specimen CLC-4-1 was reached at an axial strain which was significantly lower than that corresponding to the peak stress of the concrete in circular spirals, suggesting that the load increase due to this part of concrete was less than the load decrease of the other two parts of concrete after a certain axial strain. This was due to the relatively small area fraction of the concrete inside circular spirals in this specimen, as well as the less effective confinement that the core concrete outside spirals received.

Specimens CLA-4-1 and CLB-4-1 had approximately the same area of concrete inside the circular spirals, but the performance of the former was significantly better than the latter. This is believed to be due to the following two reasons: (1) the circular area surrounded by one spiral was larger in specimen CLB-4-1 (i.e. $100 \mathrm{~mm}$ in diameter), which led to a smaller confining pressure than that in specimen CLA-4-1 whose spirals had the same cross-section area and the same spacing; (2) the core concrete outside spirals was subjected to more effective confinement in specimen CLA-4-1. Fig. 14 shows that most of this part of concrete in specimen CLA-4-1 (i.e. the shaded area) was effectively confined by the 8 confined concrete cylinders which were placed close to each other, but this was not the case for specimen CLB-4-1.

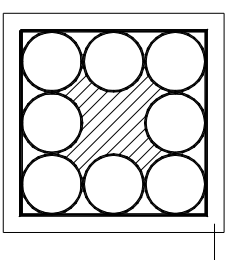

Cover concrete

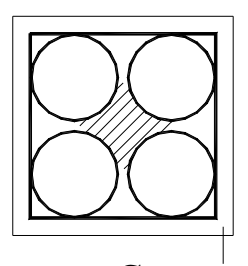

Cover concrete

Fig.14 Comparison between types A and B columns 


\subsection{Effect of spacing of circular spirals}

The axial load-axial strain curves of specimens CLA-4-1 and CLA-8-1 are compared in Fig. 15 to examine the effect of spacing of circular spirals. It is evident that specimen CLA-4-1, with the spacing of circular spirals being $40 \mathrm{~mm}$, possessed much better performance than its counterpart with a larger spiral spacing (i.e. $80 \mathrm{~mm}$ ), in terms of both the axial load capacity and the ductility (see also Table 3). This was as expected considering the significant contribution of the concrete inside circular spirals as discussed above. Further examination of the axial strain corresponding to the peak load of specimen CLA-8-1 revealed that it was also close to that corresponding to the peak axial stress of the concrete in circular spirals as predicted by Mander et al.'s [45] model. This suggests that when the area fraction of concrete in circular spirals was reasonably large (e.g. around $50 \%$ for the two specimens here), the ductility of this part of concrete was a dominant factor affecting the ductility of columns with the MTSTR, among others.

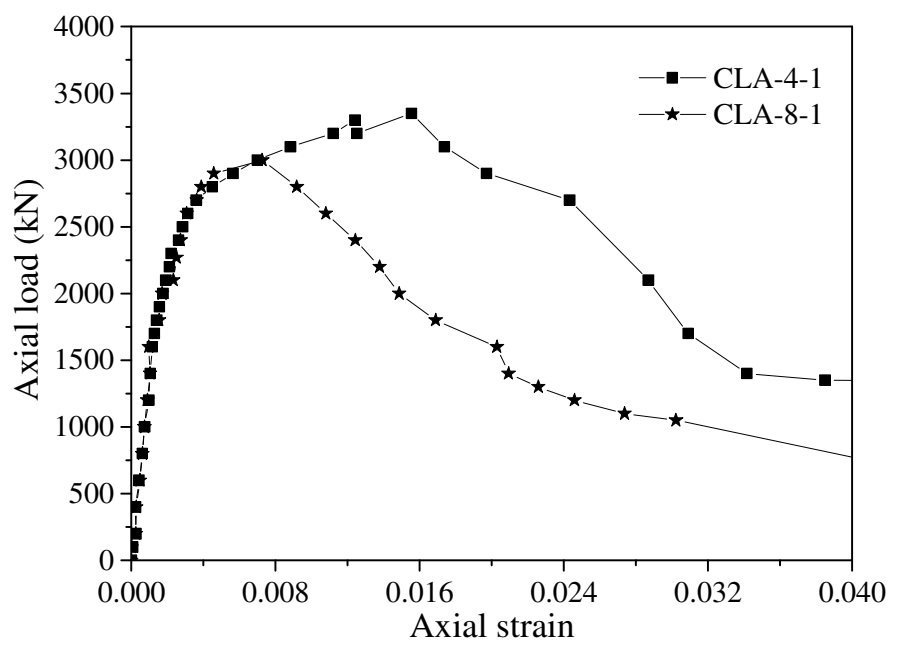

Fig.15 Effect of spacing of circular spirals 


\subsection{Effect of spacing of rectangular hoops}

The only difference between specimens CLA-4-1 and CLA-4-2 was the spacing of rectangular hoops (being $100 \mathrm{~mm}$ and $200 \mathrm{~mm}$ respectively), so their axial load-axial strain curves are compared in Fig. 16 to examine that effect. It is evident from Fig. 16 that the curves of the two are similar, with the performance of specimen CLA-4-1 being only slightly better in terms of the peak load and the corresponding strain (see also Table 3). The rectangular hoops were expected to provide confinement to the core concrete outside spirals, but the difference in such confinement in the two specimens appeared to be less significant when compared with other factors including the confinement provided by the 8 confined cylinders (see Fig. 12b). In the late stage of loading when the confined cylinders started to develop significant lateral deformation, the rectangular hoops also provided lateral constraints (see Fig. 12c) to them. This may have contributed to the larger residual strength of specimen CLA-4-1 when the deformation was large.

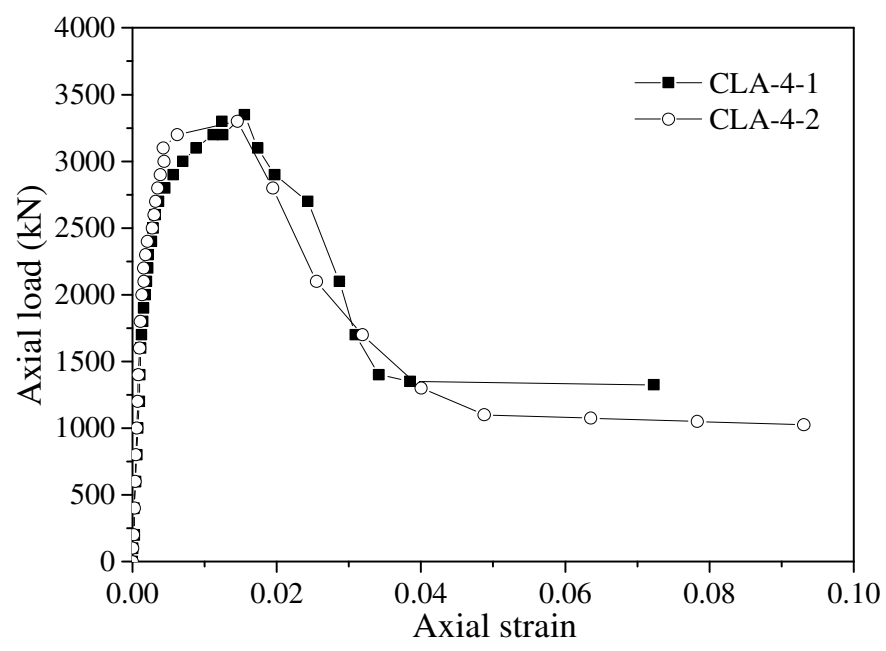

Fig. 16 Effect of spacing of rectangular hoops 


\subsection{Effect of unconfined concrete strength}

Fig. 17 shows the axial load-axial strain curves of three pairs of specimens. The only difference between the two specimens in each pair was the concrete strength. The comparison shown in Fig. 17 suggests that the effect of unconfined concrete strength in such columns was similar to that in other confined columns (e.g. columns confined by a steel tube): with a higher unconfined strength, the curves of confined concrete were normally higher, but the increases in the peak load and the corresponding axial strain were normally lower, given that the same transverse reinforcement was provided.

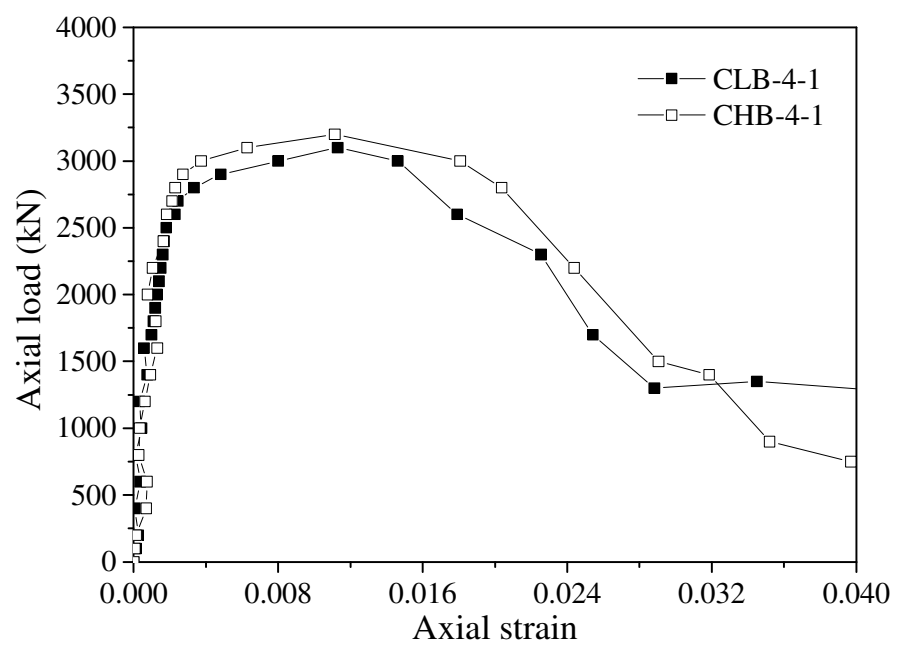

(a) Specimens CLB-4-1 and CHB-4-1 


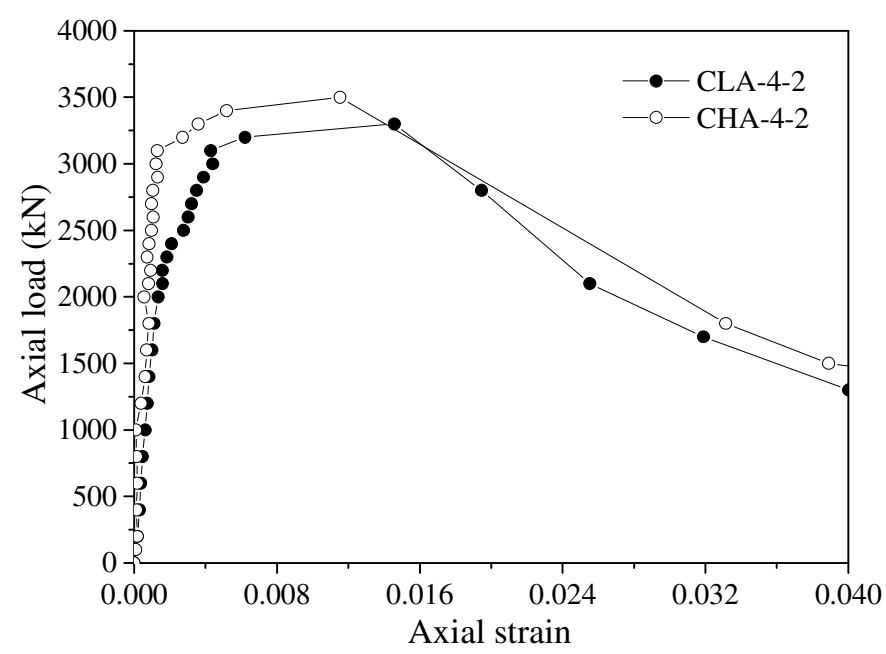

(b) Specimens CLA-4-2 and CHA-4-2

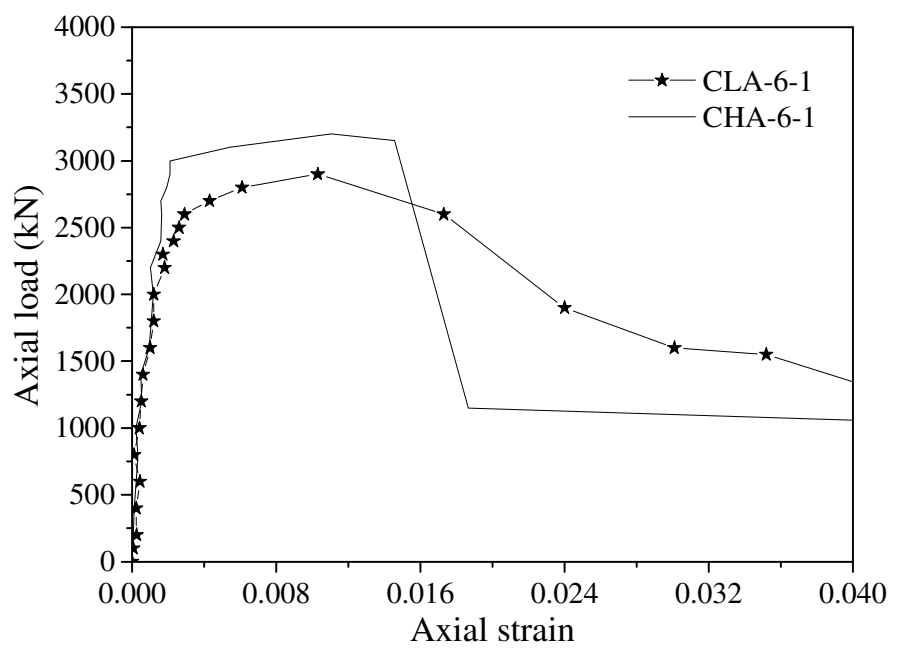

(c) Specimens CLA-6-1 and CHA-6-1

Fig.17 Effect of concrete strength

\subsection{Remarks}

It is evident from the test results and discussions above that the proposed MTSTR is a very promising solution for improved seismic performance of rectangular columns. The small cylinders confined by circular spirals were shown to not only perform very well by themselves, but also provide effective confinement to the concrete surrounded by them. Such confinement depends 
significantly on the layout of circular spirals. It appeared most effective to use a number of closely placed spirals each surrounding a small circular area, so that the confined concrete cylinders within these spirals can work together in a way similar to a thick confining wall (see Fig. 12), and the area of concrete effectively confined by these cylinders can be maximized (see Fig. 14). The confining effectiveness of these small cylinders depends much on their flexural stiffness, so a better performance can be expected when longitudinal bars are placed in the circular spirals as is the case for real practice. Future research is needed to clarify the beneficial effect of longitudinal bars on the confined concrete. The rectangular hoops play a less significant role in such columns in terms of confinement to the concrete, but they do contribute especially in the late stage of loading and for the residual strength of the column. It should also be noted that the rectangular hoops, together with the cross ties, are critical for the shear resistance of the columns as discussed earlier in the paper. To find the appropriate volume fractions of circular spirals and rectangular hoops is an optimization problem and deserves further research. The above discussions also suggest that Mander et al.'s model [45] may be used for a conservative estimation of the behavior of columns with the MTSTR, with the assumption that concrete inside spirals only received confinement from spirals while the core concrete outside spirals only received confinement from rectangular hoops. Future research needs to be conducted to develop a more rational design model for such columns when more test data becomes available.

\section{Conclusions}


This paper has presented the details of a newly proposed TRC (i.e. the MTSTR) for improved seismic performance of rectangular (including square) RC columns. The MTSTR consists of rectangular hoops, cross-ties, and additional circular spirals provided only in the potential plastic hinge regions of the column. RC columns with the MTSTR possess many advantages over existing solutions for RC columns designed for seismic loading. These advantages include excellent ductility, efficient use of longitudinal bars and ease for construction.

A series of axial compression tests were conducted to confirm some of the expected advantages with the MTSTR. These test results confirmed that both the load capacity and the ductility of RC columns can be significantly enhanced with the MTSTR. The columns were also shown to benefit significantly from the interaction between different parts of concrete (i.e. the concrete inside circular spirals and the core concrete outside spirals).

\section{Acknowledgments}

The work has been supported by the Priority Academic Program Development of Jiangsu Higher

Education Institutions as well as the Australian Research Council through a Discovery Early Career Researcher Award (Project ID: DE140101349) for the second author.

\section{References}

[1] Applied Technology Council (ATC). Seismic Evaluation and Retrofit of Concrete Buildings. ATC 40 volumes 1 and 2, Redwood City, California; 1996. 
[2] Dooley KL, Bracci JM. Seismic evaluation of column-to-beam strength ratios in reinforced concrete frames. ACI Struct J 2001; 98(6):843-851.

[3] Su J, Wang J, Bai Z, Wang W, Zhao D. Influence of reinforcement buckling on the seismic performance of reinforced concrete columns. Eng Struct 2015; 103:174-188.

[4] Feng Y, Liu L, Yi Y, Zhang S, Xiong Y, Li C. Seismic damage of frame columns in multistorey reinforced concrete buildings: investigation and learning. China Civ Eng J 2010; 43(10):63-72. (in Chinese)

[5] Sakai K, Sheikh SA. What do we know about confinement in reinforced concrete columns? (A critical review of previous work and code provisions). ACI Struct J 1989; 86(2):192-207.

[6] Teng JG, Lam L. Behavior and modeling of fiber reinforced polymer-confined concrete. J Struct Eng 2004; 130(11):1713-1723.

[7] Priestley MJN, Park R. Strength and ductility of concrete bridge columns under seismic loading. ACI Struct J 1987; 84(1):61-76.

[8] Sheikh SA, Yau G. Seismic behavior of concrete columns confined with steel and fiberreinforced polymers. ACI Struct J 2002; 99(1):72-80.

[9] Xiao Y, Sakino K,Tomii M. Ultimate moment and mechanical behavior of reinforced concrete short circular columns confined in steel tube. Trans Japan Concrete Inst 1987; 9:389-396.

[10] Xiao Y, Wu H. Retrofit of reinforced concrete columns using partially stiffened steel jackets. J Struct Eng 2003; 129(6): 725-732.

[11] Xiao Y, He W, Choi K K. Confined concrete-filled tubular columns. J Struct Eng 2005; 131(3): 488-497.

[12] Saatcioglu M, Grira M. Confinement of reinforced concrete columns with welded reinforcement grids. ACI Struct J 1999; 96(1):29-39.

[13] Lambert-Aikhionbare N, Tabsh S. Ductility enhancement of high strength concrete columns with welded wire mesh. Struct 2004; 1-20. 
[14] Eom T-S, Kang S-M, Park H-G, Choi T-W, Jin J-M. Cyclic loading tests for reinforced concrete columns with continuous rectangular and polygonal hoops. Eng Struct 2014; 67:3949.

[15] Teng JG, Yu T, Wong YL, Dong SL. Hybrid FRP-concrete-steel tubular columns: concept and behavior. Constr Build Mater 2007; 21(4):846-854.

[16] Yu T, Zhang B, Teng JG. Unified cyclic stress-strain model for normal and high strength concrete confined with FRP. Eng Struct 2015; 102:189-201.

[17] Xie T, Ozbakkaloglu T. Behavior of steel fiber-reinforced high-strength concrete-filled FRP tube columns under axial compression. Eng Struct 2015; 90:158-171.

[18] Mander JB, Priestley MJN, Park, R. Observed stress-strain behavior of confined concrete. J Struct Eng 1988; 114(8):1827-1849.

[19] Yu T, Teng JG, Wong YL, Dong SL. Finite element modeling of confined concrete-I: Drucker-Prager type plasticity model. Eng Struct 2010; 32(3):665-679.

[20] Tanaka H, Park R. Strength and ductility of reinforced concrete columns with interlocking spirals.Earthquake Engineering, Tenth World Conference, Balkema, Rotterdam, 1992; 43714376.

[21] Tanaka H, Park R. Seismic design and behavior of reinforced-concrete columns with interlocking spirals. ACI Struct J 1993; 90(2):192-203.

[22] Mclean DI, Buckingham GC. Seismic performance of bridge columns with interlocking spiral reinforcement. Final Report, Washington State Transportation Commission, Department of Transportation and in cooperation with U.S. Department of Transportation Federal Highway Administration; 1994.

[23] Khaloo AR, EI-Dash KM, Ahmad SH. Model for lightweight concrete columns confined by either single hoops or interlocking double spirals. ACI Struct J 1999; 96(6):883-891.

[24] Kim JK, Park CK. The behaviour of concrete columns with interlocking spirals. Eng Struct 
$1999 ; 21: 945-953$.

[25] Correal JF, Saiidi MS, Sanders D. Seismic performance of RC bridge columns reinforced with two interlocking spirals. Report No. CCEER-04-06, Center for Civil Engineering Earthquake Research, University of Nevada, Reno; 2004.

[26] Correal JF, Saiidi MS, Sanders D, El-Azazy S. Analytical evaluation of bridge columns with double interlocking spirals. ACI Struct J 2007; 104(3):314-323.

[27] Correal JF, Saiidi MS, Sanders D, El-Azazy S. Shake table studies of bridge columns with double interlocking spirals. ACI Struct J 2007; 104(4):393-401.

[28] Li Q, Belarbi A. Seismic behavior of RC columns with interlocking spirals under combined loadings including torsion. The Twelfth East Asia-Pacific Conference on Structural Engineering and Construction, Procedia Eng 2011; 14:1281-1291.

[29] Ou Y-C, Ngo S-H, Yin SY, Wang J-C, Wang P-H. Shear behavior of oblong bridge columns with innovative seven-spiral transverse reinforcement. ACI Struct J 2014; 111(6):1339-1349.

[30] Yin S. Researches and developments of alternative confinements for rectangular concrete columns ( I ). China Civ Eng J 2004; 37(8):1-11. (in Chinese)

[31] Yin S. Researches and developments of alternative confinements for rectangular concrete columns ( II ). China Civ Eng J 2004; 37(10):1-12. (in Chinese)

[32] Yin Y, Wen Z, Wang R, Liang J. Axial compressive behavior of precast SRC columns with multi-spirals. Eng Sci 2006; 8(12):16-30. (in Chinese)

[33] Weng C-C, Yin Y-L, Wang J-C, Liang C-Y. Axial compression and seismic behavior of precast rectangular SRC columns confined with 5-spirals. Process Steel Build Struct 2007; 9(6):12-19. (in Chinese)

[34] Weng C-C, Yin Y-L, Wang J-C, Liang C-Y. Seismic cyclic loading test of SRC columns confined with 5-spirals. Sci China Series E-Tech \& Sci 2008; 51(5):529-555.

[35] Weng C-C, Yin Y-L, Wang J-C, Shi T-H, Lu C-R. Axial and cyclic loading tests on the 
seismic performance of precast SRC columns confined with star spiral. Process Steel Build Struct 2010; 12(1):1-9. (in Chinese)

[36] Yin SY-L, Wu T-L, Liu TC, Sheikh SA, Wang R. Interlocking spiral confinement for rectangular columns. Concrete International 2011; 33(12):38-45.

[37] Yin SY-L, Wang J-C, Wang P-H. Development of multi-spiral confinements in rectangular columns for construction automation. J Chinese Inst Engrs 2012; 35(3):309-320.

[38] Hung HH, Wang PH, Yin YL, Wang JC, Chang KC. Large-scale cyclic loading test on a multi-spiral stirrup bridge pier constructed by automated method. 15 WCEE, Lisboa; 2012.

[39] Chen Y, Feng J, Yin S. Compressive behavior of reinforced concrete columns confined by multi-spiral hoops. Comput Concrete 2012; 9(5):341-355.

[40] Shih T-H, Chen C-C, Weng C-C, Yin SY-L, Wang J-C. Axial strength and ductility of square composite columns with two interlocking spirals. J Constr Steel Res 2013; 90:184-192.

[41] Wu T-L, Ou Y-C, Yin SY-L, Wang J-C, Wang P-H, Ngo S-H. Behavior of oblong and rectangular bridge columns with conventional tie and multi-spiral transverse reinforcement under combined axial and flexural loads. J Chinese Inst Engrs 2013; 36(8):980-993.

[42] Watson S, Park R. Simulated seismic load tests on reinforced concrete columns. J Struct Eng 1994; 120(6):1825-1849.

[43] Razvi SR, Saatcioglu M. Strength and deformability of confined high-strength concrete columns. ACI Struct J 1994; 91(6):678-687.

[44] Shao Y, Zhu Z, Mirmiran A. Cyclic modeling of FRP-confined concrete with improved ductility. Cement Concrete Comp 2006; 28:959-968.

[45] Mander JB, Priestley MJN, Park R. Theoretical stress-strain model for confined concrete. J Struct Eng 1988; 114(8):1804-1826.

[46] GB/T 50081-2002. Standard for test method of mechanical properties on ordinary concrete. China Architecture \& Building Press, Beijing, China; 2003. 
[47] GB/T 228.1-2010. Metallic materials-tensile testing-part 1: method of test at room temperature. Standards Press of China, Beijing, China; 2010. 